Respiration 2017;93:151-152

DOI: $10.1159 / 000454839$

\section{Is Procalcitonin Really Useful for Diagnosis and Prognosis of COPD Exacerbations Requiring Mechanical Ventilation?}

\author{
Matteo Giorgi-Pierfranceschi ${ }^{\mathrm{a}}$ João Cravo ${ }^{\mathrm{b}}$ Francesco Dentalic \\ Antonio M. Esquinas ${ }^{d}$ \\ ${ }^{a}$ Emergency Department, Hospital of Val d'Arda, Piacenza, Italy;

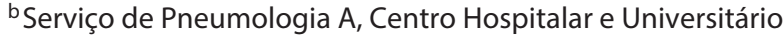 \\ de Coimbra, Coimbra, Portugal; ' ${ }^{\mathrm{D}}$ Department of Internal and \\ Experimental Medicine, University of Insubria, Varese, Italy; \\ dIntensive Care and Non-Invasive Ventilatory Unit, Hospital \\ Morales Meseguer, Murcia, Spain
}

In the last 2 decades, serum procalcitonin (PCT) has played a widely accepted role in the diagnosis of sepsis due to bacterial agents. Recently, the clearance of serum PCT has been shown to be useful in driving the duration of antibiotic therapy in patients affected by pneumonia [1] or COPD exacerbation (COPDE) [2, 3], but these latter findings require further confirmation. Finally, the role of PCT in diagnosis and prognosis among critically infectious patients is still controversial.

Ergan et al. [4] have recently published a retrospective monocentric study including 63 patients admitted to ICU for severe COPDEs requiring mechanical ventilations (noninvasive ventilation or invasive mechanical ventilation).

In this study, the authors attributed a diagnostic and prognostic role to PCT values. The primary aim was to determine whether the level of serum PCT at admission had a prognostic value for hospital mortality. The secondary aim was to determine the role of PCT in identifying a bacterial exacerbation. They showed that admission PCT levels were useful in estimating hospital mortality for those patients, and that a PCT level $<0.25 \mathrm{ng} / \mathrm{ml}$ at the time of admission and during follow-up was suggestive of a non-bacterialrelated cause of the exacerbation.

A previous study evaluated the meaning of positive values of PCT using a different cutoff $(>0.5 \mathrm{ng} / \mathrm{ml})$ when prospectively assessing the bacterial involvement in severe COPDE, but these authors revealed further criteria, such as positive endotracheal aspirate, to have a better accuracy, with a good negative predictive value (NPV) (95\%) [5]. In 2012, Schuetz et al. [6] analyzed pooled data about 14 trials, including 4,221 patients with varying severity of acute respiratory tract infections and from different clinical settings, and evaluated the use of the PCT value in guiding initiation and duration of antibiotic treatment. They compared the safety and efficacy of a PCT-guided versus a standard of care approach. The results of this analysis did not show a correlation between the PCT-driven decision to prescribe antibiotics and a higher rate of mortality or treatment failure, but most of the patients were enrolled in a primary care or emergency department setting, and the adherence to the protocol algorithm ranged from 47 to $91 \%$. Finally, the authors suggested to use PCT values to exclude acute respiratory infections in patients at low risk of severe bacterial infections (primary care and emergency room settings), while in patients at higher risk (intensive care setting) PCT should be used to determine when antibacterial treatment could be safely discontinued [7]. More recently, Kutz et al. [8] published another interesting analysis based on the same pooled database, evaluating over 4,000 patients with acute respiratory tract infections, in which they investigated the prognostic value of admission PCT levels to predict an adverse outcome (treatment failure and mortality) in patients with acute respiratory tract infections. They concluded that this biomarker had the best ability to predict treatment failure in the emergency setting; in contrast, in the primary and intensive care settings they did not find any significant correlation between PCT levels and poor outcome. Moreover, in patients admitted for COPDE, it was found that PCT levels (cutoff $0.25 \mathrm{ng} / \mathrm{ml}$ ) had a predictive value for treatment failure (positive predictive value [PPV] 23\%; NPV 88\%) and mortality (PPV 8\%; NPV 98\%).

In their study, Ergan et al. [4] showed an NPV of $80 \%$ using only the PCT value. Moreover, in this retrospective monocentric study, the authors concluded that PCT levels higher than $0.25 \mathrm{ng} /$ $\mathrm{ml}$, generally used for non-ICU patients [1], had a prognostic relevance in estimating hospital mortality in that setting, but in their analysis of 63 cases of COPDE, 15 patients died (23\%) during hospitalization, but 5 of them (one-third of the total) had PCT values lower than $0.25 \mathrm{ng} / \mathrm{ml}$, confirming a low NPV for this biomarker.

In conclusion, PCT levels alone seem not to be able to exclude or confirm, with a sufficient accuracy, the bacterial etiology of exacerbations. Moreover, concerning the prediction of hospital mortality, a negative $(<0.25 \mathrm{ng} / \mathrm{ml})$ PCT has a poor predictive value, as recently demonstrated in septic patients [9], but further studies in severe COPDEs requiring mechanical ventilation support are needed to confirm these findings. However, PCT is not specific for sepsis, and values need to be interpreted in the context of a full clinical evaluation [10]. Certainly, for critically ill patients requiring mechanical ventilation in whom hypercapnia could be a very important factor related to mortality, research into better diagnostic workouts and prognostic factors is necessary, but the clinical complexity of these individuals requires assessing scores including many items (demographic, clinical, laboratory) to define useful tools for making clinical decisions with a good and practical accuracy.

\section{KARGER}

(C) 2017 S. Karger AG, Basel

E-Mail karger@karger.com

www.karger.com/res
Matteo Giorgi-Pierfranceschi, MD

Emergency Department, Hospital of Val d'Arda Via Roma

IT-29017 Fiorenzuola d'Arda (Piacenza) (Italy)

E-Mailm.giorgi@ausl.pc.it 


\section{References}

1 Fazili T, Endy T, Javaid W, Maskey M: Role of procalcitonin in guiding antibiotic therapy. Am J Health Syst Pharm 2012;69:2057-2061.

2 Van der Maas M, Steuten L: A PCT-algorithm to guide antibiotic therapy in patients hospitalized with COPD exacerbations leads to net cost savings by reducing frequency and duration of antibiotic use as compared to current practice. Value Health 2015;18.

3 Verduri A, Luppi F, D’Amico R, Balduzzi S, Vicini R, Liverani A, Ruggieri V, Plebani M, Barbaro MP, Spanevello A, Canonica GW, Papi A, Fabbri LM, Beghè B; FARM58J2XH Study Group: Antibiotic treatment of severe exacerbations of chronic obstructive pulmonary disease with procalcitonin: a randomized noninferiority trial. PLoS One 2015;10: e0118241.

4 Ergan B, Şahin AA, Topeli A: Serum procalcitonin as a biomarker for the prediction of bacterial exacerbation and mortality in severe COPD exacerbations requiring mechanical ventilation. Respiration 2016;91:316324.

5 Nseir S, Cavestri B, Di Pompeo C, Diarra M, Brisson H, Lemyze M, Roussel-Delvallez M, Durocher A: Factors predicting bacterial involvement in severe acute exacerbations of chronic obstructive pulmonary disease. Respiration 2008;76:253-260.
6 Schuetz P, Briel M, Christ-Crain M, Stolz D, Bouadma L, Wolff M, Luyt CE, Chastre J, Tubach F, Kristoffersen KB, Wei L, Burkhardt O, Welte T, Schroeder S, Nobre V, Tamm M, Bhatnagar N, Bucher HC, Mueller B: Procalcitonin to guide initiation and duration of antibiotic treatment in acute respiratory infections: an individual patient data meta-analysis. Clin Infect Dis 2012;55:651-662.

7 Schuetz P, Müller B, Christ-Crain M, Stolz D, Tamm M, Bouadma L, Luyt CE, Wolff M, Chastre J, Tubach F, Kristoffersen KB, Burkhardt O, Welte T, Schroeder S, Nobre V, Wei L, Bhatnagar N, Bucher HC, Briel $\mathrm{M}$ : Procalcitonin to initiate or discontinue antibiotics in acute respiratory tract infections. Cochrane Database Syst Rev 2012;CD007498.

8 Kutz A, Briel M, Christ-Crain M, Stolz D, Bouadma L, Wolff M, Kristoffersen KB, Wei L, Burkhardt O, Welte T, Schroeder S, Nobre V, Tamm M, Bhatnagar N, Bucher HC, Luyt CE, Chastre J, Tubach F, Mueller B, Schuetz P: Prognostic value of procalcitonin in respiratory tract infections across clinical setting. Crit Care 2015;19:74.

9 Huang MY, Chen CY, Chien JH, Wu KH, Chang YJ, Wu KH, Wu HP: Serum procalcitonin and procalcitonin clearance as a prognostic biomarker in patients with severe sepsis and septic shock. Biomed Res Int 2016;2016:1758501.

10 Vincent JL, Van Nuffelen M, Lelubre C: Host response biomarkers in sepsis: the role of procalcitonin. Methods Mol Biol 2015;123:213-224. 